Original Article

\title{
IMPACT OF PATIENT COUNSELLING ON KNOWLEDGE, ATTITUDE, AND PRACTICE OF HYPERTENSIVE PATIENTS IN A TERTIARY CARE HOSPITAL
}

\author{
JUNA ANN THOMAS ${ }^{1}$, KAKANI SAI SNIGDHA ${ }^{1}$, PREETHY MATHEW KARANATH ${ }^{2}$, ANN MARY SWAROOP2* \\ ${ }^{1,2}$ Department of Pharmacy Practice, Faculty of Pharmacy, M. S. Ramaiah University of Applied Sciences, M. S. R. I. T Post, Bengaluru-54, \\ Karnataka, India \\ Email: annmary103@gmail.com
}

Received: 22 Mar 2017 Revised and Accepted: 13 Jul 2017

\begin{abstract}
Objective: Hypertension is a leading cause of death and disability worldwide and proper assessment of knowledge, attitude, and practice (KAP) factors are helpful in its management. Our aim was to assess the knowledge, attitude, and practice among hypertensive patients and the impact of patient counselling on the same.

Methods: A prospective study was conducted among hypertensive patients from November 2015 to April 2016 . Suitably designed and validated KAP questionnaire was used to evaluate the baseline KAP score. Patient information leaflets were provided after counselling. After 3 mo patients
\end{abstract} were followed up and their KAP scores were reassessed and data were analysed.

Results: Before the intervention, the mean score $\pm S D$ of knowledge, attitude, and practice were $11.76(S D \pm 4.58) ; 5.14(S D \pm 2.13)$; $9.26(S D \pm 1.66)$ which increased to $14.29(\mathrm{SD} \pm 2.95) ; 5.74(\mathrm{SD} \pm 1.39) ; 10.32(\mathrm{SD} \pm 1.33)$ respectively after the intervention.

Conclusion: Our study suggests that pharmacist mediated counselling plays a vital role in improving patients' knowledge, attitude, and practice towards the disease management.

Keywords: Hypertension, Knowledge, Attitude, Practice, Patient counselling

(C) 2017 The Authors. Published by Innovare Academic Sciences Pvt Ltd. This is an open access article under the CC BY license (http://creativecommons.org/licenses/by/4.0/) DOI: http://dx.doi.org/10.22159/ijpps.2017v9i9.19881

\section{INTRODUCTION}

The prevalence of non-communicable diseases (NCD) is escalating nationally and globally accounting a major challenge to development [1]. Hypertension (HTN) is such an NCD which has become a serious public health problem and a leading cause of death and disability in developing countries [2]. Approximately $26 \%$ of the adult population in the world have been affected by hypertension. This number is estimated to increase to $29 \%$ by 2025 that is, from 972 million as of the year 2000 to 1.56 billion [3]. Recent studies conducted in India estimate the presence of 66 million hypertensive patients, accounting for $25 \%$ of adults in urban areas, and $10 \%$ in rural areas [4]. In a survey conducted in South India among 26,000 adults, the prevalence of hypertension was found to be $20 \%$. It was also observed that the prevalence was comparatively higher in men (23\%) than in women (17\%) [5]. The increasing prevalence of hypertension is mainly due to lack of understanding about the disease, insufficient patient education programs, low economic status etc. which might even lead to medication non-adherence. Uncontrolled hypertension often causes issues like higher morbidity and increased health care costs [3]. This calls for urgent prevention and control measures for hypertension [5].

A proper assessment and understanding of knowledge, attitude, and practice (KAP) factors are helpful in the area of chronic conditions such as hypertension, for which prevention and control are necessary along with the lifelong adoption of a healthy lifestyle [6].

Knowledge is a set of understandings whereas attitude is a way of being and is an intermediate variable between the situation and the response to this situation. Practices or behaviours are the observable actions of an individual in response to a stimulus.

Knowledge about hypertension care is essential for achieving the desired goal. Adequate knowledge about a disease has a potential impact on the patients' attitude and practice in the management of their illnesses. So it is important to assess the extent to which patients are aware of their blood pressure levels [7].
Regardless of the availability of effective drug therapy, there is a high burden of hypertension and related complications which could be due to the lack of patients' understanding of the disease and lifestyle modifications. Necessary information about the treatment and other aspects can be understood only when the patients are educated well. Pharmacists can play an important role in achieving positive therapeutic outcomes by motivating patients to adhere to the treatment.

Patient counselling can be provided verbally or in written form to the patients or caretakers regarding medications, its directions of use, advice on side effects, storage, diet and lifestyle modifications. Patient information leaflet (PIL) which is prepared by the manufacturer or the pharmacist can be beneficial and is an accepted tool to educate the patient [3].

Hence this study was an attempt to assess the effectiveness of counselling on hypertensive patients in terms of KAP outcomes in M. S. Ramaiah Hospitals.

\section{MATERIALS AND METHODS}

\section{Methodology}

A longitudinal observational study was conducted for a period of 6 mo from November 2015 to April 2016 in the wards of General Medicine, Cardiology and Nephrology units of M. S. Ramaiah Hospitals, Bangalore. The study enrolled hypertensive patients with or without other comorbidities of either gender aged $\geq 18 \mathrm{y}$. Pregnant and lactating women, paediatric population, patients with severe chronic illness and patients in intensive care units were excluded from the study. A total of 105 patients were enrolled in the study, but only 96 were able to complete the study. Remaining 9 patients could not be followed up due to technical difficulties. The sample size was calculated based on a similar study conducted in Pune. The study has been approved by the Institutional Ethical Committee. The registration number of the ethics committee is $\mathrm{ECR} / 215 /$ Inst/Ker/2013 and the reference number of the study is MSRMC/EC/2016. 


\section{KAP questionnaire}

A validated KAP questionnaire was used to carry out the study. The pre-validation was done via conducting a pilot study in 20 subjects through face validation, content validation, and criterion validation. Socio-demographic parameters of patients such as gender, age, educational qualification, body mass index, smoking, alcohol, diet and salt preference were included in the questionnaire, followed by knowledge, attitude and practice questions. There was a total of 42 questions, with 18 questions related to knowledge about hypertension, 7 questions to assess the attitude of the patient towards the disease, and 17 questions regarding practices. This questionnaire was filled by conducting a face-to-face interview.

\section{Scoring method}

Based on the interview, the knowledge levels of the patients were assessed using scores ranging from 0-18 indicating minimum to maximum score. In the scoring method, 18 were the maximum possible score for knowledge and each correct answer carried one score and incorrect or unsure answer carried no score. Knowledge scores were divided into excellent (16-18), good (12-15), fair (9-11), and poor (0-8). The attitude of the patient was assessed using score ranging from-7 to +7 indicating the minimum and maximum score. In attitude +1 was given for positive answer, -1 for a negative answer and 0 for neutral. The attitude was classified as positive if total score was above 0 , neutral for 0 score and negative if total score was less than 0 . Out of 17 questions in the practice section, the scoring was given only for 12 relevant questions. The maximum score given for practice was 12 and each correct answer carried one score and no score for the unsure or wrong answer. Practice scores were divided into good (11-12), adequate (8-10) and inadequate (0-7).

After obtaining the consent of the patients, a patient interview was conducted using the KAP questionnaire. Demographic data and details regarding the current treatment were collected. Baseline KAP scores were noted and accordingly, patient counselling was given. Patients were educated about the disease and its management, its complications, lifestyle modifications and the importance of medication adherence with the help of patient information leaflet (PIL). Further follow ups and counselling were done after 3 mo on patient visits for their review or telephonically and KAP score of patients was again measured using the same KAP questionnaire to identify the chances of improvement in KAP scores. The obtained scores were noted and the pre-and post-counselling results were compared. Similarly, the improvement in their knowledge, attitude, and practice before and after patient counselling was assessed.

\section{Statistical analysis}

Paired sample T-test was used to assess the improvement in knowledge, attitude and practice in hypertensive patients before and after patient counselling and data were analysed using SPSS software version 20.0. $\mathrm{P}<0.001$ was considered highly significant.

\section{RESULTS}

Among 105 patients, 59 (56.2\%) were males and 46 (43.8\%) were females. Mean age of the study population was calculated to be 55.25 ( $S D \pm 13.07)$. Mean age of males was found to be 55.16 ( $\mathrm{SD} \pm 14.67$ ) and that of females was $55.30(\mathrm{SD} \pm 10.98)$. Minimum age in the study was found to be $20 \mathrm{y}$ and maximum age was $80 \mathrm{y}$. About 52 (49.5\%) subjects were found to be in the age group of 40-59 y with almost equal numbers of males and females, followed by $42(40 \%)$ who were above $60 \mathrm{y}$ and only $11(10.47 \%)$ were found in the age group of 20-39 y. Mean body mass index (BMI) among the study population was found to be 24.72 (SD \pm 3.05$)$. About 57 (54.3\%) patients were found to have normal BMI and $43(41 \%)$ were overweight patients. Only $4(3.8 \%)$ patients were found to be obese. Out of total population, about $53(50.5 \%)$ preferred a moderate amount of salt whereas about $37(35.2 \%)$ of the participants preferred more salt. About 15 (15.2\%) of them had the tendency to consume less salt. Out of the total population, $76(72.4 \%)$ were nonsmokers and $20(19 \%)$ subjects admitted that they had a previous history of smoking. Our study found that $72(69 \%)$ of the patients were nonalcoholic and $22(21 \%)$ patients had a previous history of alcohol intake. About $11(10 \%)$ patients were on regular alcohol intake.

The most prevalent comorbidity among the study population was found to be diabetes mellitus (DM). About 34 (32.4\%) had DM alone and $25(23.8 \%)$ had DM along with other diseases such as kidney and heart diseases. Comorbidities like thyroid disorders, lower respiratory tract infection, upper respiratory tract infections, urinary tract infections and osteoarthritis were also observed in some patients.

The mean scores \pm standard deviation of knowledge; attitude and practice were increased significantly after the intervention. The knowledge of patients was $65.3 \%$ before patient counselling which was increased to $79.4 \%$ after patient counselling. The attitude before patient counselling was found to be $73.4 \%$ which was increased to $82 \%$ after patient counselling. The practice of patients was $77.2 \%$ before patient counselling which was increased to $86 \%$ after patient counselling. (table 1,2, 3 and 4).

Table 1: Comparison of mean knowledge, attitude, and practice scores of the study population

\begin{tabular}{llll}
\hline Parameters & Before counselling (\%) & After counselling (\%) & P-value* \\
\hline Knowledge & $11.76 \pm 4.58(65.3 \%)$ & $14.29 \pm 2.95(79.4 \%)$ & $\mathrm{P}<0.001$ \\
Attitude & $5.14 \pm 2.13(73.4 \%)$ & $5.74 \pm 1.39(82 \%)$ & $\mathrm{P}<0.001$ \\
Practice & $9.26 \pm 1.66(77.2 \%)$ & $10.32 \pm 1.33(86 \%)$ & $\mathrm{P}<0.001$ \\
\hline
\end{tabular}

Values are expressed as mean \pm SD, $*$-Highly significant $(n=96)$

Table 2: Distribution of knowledge before and after patient counselling

\begin{tabular}{lllll}
\hline Category & Before & & After & \\
\cline { 2 - 5 } & (n= 96) & Percentage (\%) & (n= 96) & Percentage (\%) \\
\hline Poor & 26 & 28.2 & 6 & 6.3 \\
Fair & 17 & 17.7 & 9 & 9.4 \\
Good & 29 & 30.2 & 42 & 43.8 \\
Excellent & 24 & 26.1 & 39 & 40.6 \\
\hline
\end{tabular}

Table 3: Distribution of attitude before and after patient counselling

\begin{tabular}{lllll}
\hline Category & Before & & After & \\
\cline { 2 - 5 } & $\mathbf{( n = 9 6 )}$ & Percentage (\%) & (n=96) & Percentage (\%) \\
\hline Positive & 91 & 94.8 & 96 & 00 \\
Neutral & 1 & 1 & 0 & 0 \\
Negative & 4 & 4.2 & 0 & 0 \\
\hline
\end{tabular}


Table 4: Distribution of practice before and after patient counselling

\begin{tabular}{lllll}
\hline Category & Before & & After \\
\cline { 2 - 5 } & (n=96) & Percentage (\%) & (n =96) & Percentage (\%) \\
\hline Inadequate & 13 & 13.5 & 4 & 4.2 \\
Adequate & 63 & 65.7 & 41 & 42.7 \\
Good & 20 & 20.8 & 51 & 53.1 \\
\hline
\end{tabular}

\section{DISCUSSION}

Our study primarily assessed the knowledge, attitude, and practice (KAP) among hypertensive patients and also the impact of patient education on the same.

The number of male patients enrolled in our study was higher than the number of female patients and this was similar to a study conducted in Guntur [8]. Most of the patients belonged to the age group of 40-59 y with no much difference between the number of males and females. Younger patients were more aware of hypertension and its complications than older patients. Hence the rate was less among patients aged between 20-39 y.

Elevated BMI is an important risk factor for the development of hypertension and is an indicator of sedentary lifestyle. Most of the respondents in our study belonged to the normal BMI category, followed by overweight patients. These results were almost similar to those reported in the study conducted in Mandya, Karnataka [9]. Numerous studies have proven that hereditary nature of hypertension is an important non-modifiable risk factor. But this information was contradictory to the findings of studies conducted in Nepal [10]. These studies showed that there was a negative family history of the disease in the population which was similar to the findings of our study.

Education is an indicator of knowledge that the patient has regarding the disease conditions. The overall percentage of educated patients was found to be high in the present study. Thus literacy can be considered as a pointer to blood pressure control as educated people were able to understand the complications more effectively.

Changes in dietary patterns and lifestyle are contributing to the rapid increase in the prevalence of hypertension. The Indian cuisine requires high usage of salt while cooking and involves a habit of adding extra salt at the table [11]. About 35.2\% of the study population had a habit of high intake of papads, chutneys, and pickles which are foods rich in salt content. This might pose an additional risk of causing elevated BP levels. Similar findings were reported from another study [12]. The increase in salt intake is associated with increased risk for hypertension and reduction in salt intake can be the most cost-effective method to reduce the burden of hypertension.

In our study hypertension was found to be more in males. This might be suggestive of the association between the disease and social habits like smoking and alcohol consumption among male patients. Most of our study population were reluctant to admit their social habits.

Diabetes is also an NCD which when becomes uncontrolled damages arteries and hardens them which increases the chances of developing HTN. Current study observed more cases of Diabetes Mellitus as the comorbid condition which was found to be in agreement with the findings of a similar study [14].

Knowledge regarding a disease is very important for its proper management. Pre and post-tests in the present study suggested that the differences are statistically significant $(p<0.001)$. The mean knowledge was increased after the patient counselling (table 1, 2). This finding was similar to the previous study [10]. This suggests that educational intervention and pharmacist counselling has a role in improving the knowledge scores which was concordant to the findings of the study conducted in Pune [3]. It was identified that overall knowledge score in our population was insufficient which needs to be improved by educational programmes.

According to health belief model, the individual's perception of a disease and likelihood of adoption of positive attitude and practices depend on four parameters such as perceived seriousness of a disease, perceived susceptibility to a disease, perceived benefits of positive attitude and practice, and perceived barriers that prevent the individuals from making the positive changes [5].

The mean attitude score before patient counselling was positive. These findings were similar to an Iranian study which also observed a good attitude score in the population [15]. There was a significant improvement in the attitude score after patient counselling (table 1, 3) which was concordant to the findings of another study [4]. The mean percentage attitude in our study was $73.4 \%$, which was higher than the mean percentage knowledge $65.3 \%$.

Though a patient has good knowledge and positive attitude, outcome differs with the practice. In the present study mean practice score was increased after the counselling (table 1,4). This shows that the study population had an adequate practice overall. The mean percentage practice score in our study was comparable to the findings from a study conducted in Iran [15]. In comparison to the knowledge scores, the attitude and practice scores were not increased to a great extent, which might be due to short follow-up period of $3 \mathrm{mo}$ in our study. These results were coinciding with another study in which significant improvement was not achieved with the attitude and practice scores as that of the knowledge scores [10]. The present study showed that patient counselling led to the improvement in practice scores which was comparable to the study conducted in Karnataka [4]. Better practices can make huge differences in the burden of the disease. This change in practice mainly involves lifestyle changes which are possible through the educational programs provided by the healthcare professionals.

A significant improvement $(p<0.001)$ was seen in the mean knowledge, attitude and practice scores before and after patient counselling (table 1). Similar to many studies, our study findings also suggest that clinical pharmacist mediated counselling improved the knowledge, attitude, and practice outcomes in hypertensive patients.

\section{CONCLUSION}

The burden of non-communicable diseases such as hypertension is increasing in developing countries and is a significant public health problem in both urban and rural areas. Therefore proper education and awareness programs should be developed according to the need of the society which in turn would improve the knowledge of general population and will definitely bring about a positive change in attitude and practices.

The present study emphasizes the potential role of the pharmacist as a patient educator to increase awareness about the importance of both pharmacological and non-pharmacological control of hypertension which improves the KAP scores. This study throws light on the impact of pharmacist mediated patient counseling in improving knowledge, attitude, and practice among hypertensive patients.

\section{LIMITATIONS}

- $\quad$ Few of the study participants were reluctant to admit their poor knowledge, attitude, and practices in order to avoid a negative impression

- The study cannot be fully generalizable

- Study results cannot be extrapolated to pediatrics and pregnant population

\section{ACKNOWLEDGEMENT}

We acknowledge Dr. V Madhavan, Dean and Principal, Dr. E. Maheswari, Professor and Head of Department of Pharmacy 
Practice, Faculty of Pharmacy, M. S. Ramaiah University of Applied Sciences and Dr. Ashwin Kulkarni, Assistant Professor, M. S. Ramaiah Hospitals for their continuous support and encouragement.

\section{AUTHORS CONTRIBUTION}

Juna Ann Thomas and Kakani Sai Snigdha collected the data, did the statistical analyses and wrote the first draft of this paper. The study was done under the guidance of Mrs. Preethy Mathew Karanath and the paper was edited by Dr. Ann Mary Swaroop for important content. All authors reviewed and provided comments on subsequent iterations.

\section{CONFLICT OF INTERESTS}

Declared none

\section{REFERENCES}

1. Hameed AL, Ebid M, Zina TA, Mohamed AFG. Blood pressure control in hypertensive patients: impact of an Egyptian pharmaceutical care model. J Appl Pharm Sci 2014;4:93101.

2. Roopa KS, Rama Devi G. Impact of intervention programme on knowledge, attitude, practices in the management of hypertension among elderly. Studies Home Community Sci 2014;8:11-6.

3. Pawar S, Kaveri DL, Padma S, Diwan A. Effect of pharmacist mediated patient counselling in hypertensive patients in terms of knowledge, compliance and lifestyle modification. Int J Pharm Pharm Sci 2014;6:277-81.

4. Ramesh A, Somasekhar MA. Influence of structured patient education on therapeutic outcomes in diabetes and hypertensive patients. Asian J Pharm Clin Res 2010;3:174-8.

5. Biradar SS, Reddy S, Raju SA, Kapatae R. Assessment of pharmacist mediated patient counselling on knowledge, attitude, and practices on hypertension in compliance with antihypertensive drugs in South Indian city. Int J Pharm Life Sci 2012;3:1733-8.

6. Parmar P, Gunvanti B, Rathod, Sangita R, Goyal R, Aggarwal S, et al. Study of knowledge, attitude and practice of general population of gandhinagar towards hypertension. Int J Curr Microbiol Appl Sci 2014;3:680-5.
7. Biradar SS, Reddy S, Raju SA, Kapatae R. Role of pharmacist towards knowledge, attitude, and practice in compliance with hypertension in north Karnataka in south Indian city a brief overview. Int Res J Pharm 2012;3:17-20.

8. Bollu M, Nalluri KK, Prakash AS, Lohith MN, Venkataramarao N. Study of knowledge, attitude, and practice of general population of guntur toward silent killer diseases: hypertension and diabetes. Asian J Pharm Clin Res 2015;8:74-8.

9. Ramanath KV, Balaji DBSS, Nagakishore CH, Mahesh Kumar S, Bhanuprakash M. A study on impact of clinical pharmacist interventions on medication adherence and quality of life in rural hypertensive patients. J Young Pharm 2012;4:95-100.

10. Sharma S, Aarati K, Bharat P, Roshani S, Sunil S, Kalpana P, et al. Knowledge, Attitude and Practice outcomes: an effect of pharmacist provided counselling in hypertensive patients in a tertiary care teaching hospital in western Nepal. Int J Pharm Sci 2010;2:583-7.

11. Johnson C, Mohan S, Rogers K, Roopa S, Sudhir R, Priti G, et al. Mean dietary salt intake in urban and rural areas in india: a population survey of 1395 persons. J Am Heart Assoc 2017;6:1-8.

12. Ghosh A, Sarkar D, Mukherji B, Pal R. Prevalence, and risk correlates of hypertension among adult rural population in Bihar. Ann Trop Med Public Health 2013;6:71-5.

13. Shankar P, Bhatia S, Khanka BS, Singh D, Tutu S, Lakhani P, et al. Study of knowledge, attitude and practice of general population of Lucknow towards hypertension. World J Pharm Pharm Sci 2015;4:1674-9.

14. Naveen B, Mahaboojan M, Padmanabha YR, Narayana G. Impact of clinical pharmacist mediated patient counselling on health related quality of life in hypertensive patients. Indian J Pharmacy Practice 2014; 7:34-40.

15. Sabouhi F, Babaee S, Naji H, Zadeh AH. Knowledge, awareness, attitudes, and practice about hypertension in hypertensive patients referring to public health care centers in Khoor and Biabanak. Iranian J Nursing Midwifery Res 2011;16:34-40.

\section{How to cite this article}

- Juna Ann Thomas, Kakani Sai Snigdha, Preethy Mathew Karanath, Ann Mary Swaroop. Impact of patient counselling on knowledge, attitude, and practice of hypertensive patients in a tertiary care hospital. Int J Pharm Pharm Sci 2017;9(9):122-125. 